\title{
FORMAÇÃO INTERDISCIPLINAR DE PROFESSORES DE ADMINISTRAÇÃO
}

\author{
Cláudio Antônio Tordino'
}

\begin{abstract}
Resumo
O aumento de escopo da área tem levado a Administração à constituição de subáreas especializadas, em detrimento da visão de conjunto, cada vez mais requerida. Essa fragmentação compele à inclusão de novas disciplinas nos currículos dos cursos de graduação em Administração, com o fito de mantê-los atualizados. Parece, contudo, que a multiplicidade de disciplinas mais tem gerado perplexidades do que propiciado a professores e estudantes a ambicionada compreensão do todo. Este texto discute a idéia de que o sucesso de um curso de graduação em Administração pode depender da formação abrangente e integrada de seus professores. A alternativa proposta é a da adoção de programa de formação de professores calcado em abordagem interdisciplinar e aprendizagem com pesquisa, para que, dessa experiência por eles vivida, obtenham visão compreensiva das áreas de Administração, independentemente das disciplinas que ministrem, e encontrem caminhos para práticas consistentes e conseqüentes que levem à autonomização dos estudantes.
\end{abstract}

Palavras-chave: Formação de Professores de Administração. Ensino de Administração; Aprendizagem de Administração. Interdisciplinaridade em Administração. Ensino com Pesquisa em Administração.

\section{INTRODUÇÃO}

As pessoas são ensinadas a esquecer os conflitos objetivos que necessariamente se repetem em cada indivíduo, ao invés de serem ajudadas a lidar com eles.

T. W. Adorno

A expressividade numérica dos cursos de graduação em Administração no Brasil, a envolver mais de 2.000 cursos, de 500 mil estudantes e de 25 mil docentes, enseja

\footnotetext{
' Economista (USP), Administrador (FASP), Mestre em Educação (USP e PUC-SP), Doutorando em Educação (USP e PUC-SP) Endereço: Rua Itapicuru, 5 I 4 apto. 802. São Paulo - 05006-000. Email: ctordino@amcham.com. Artigo recebido em: 21/02/2006. Aprovado em: 22/03/2007. Membro do Corpo Editorial Científico responsável pelo processo editorial: Prof. João Nilo Linhares.
} 
reflexões; entre outras, sobre o papel que a área de Administração vem desempenhando no Ensino Superior, sobre o processo de ensino-aprendizagem adotado nos cursos de graduação e, também, sobre a formação de professores. Longe de apenas representar pujança, a grandeza dos números revela, em contrapartida, insatisfação com relação ao acervo de conhecimentos dos graduados - claramente indicada, primeiro, em todas as edições do Exame Nacional de Cursos, em que a média dos graduandos sempre se posicionou do grau quatro para baixo, e agora, nos resultados do ENADE -, e com as dificuldades de engajamento dos formados nas organizações, em posições que seriam típicas de administradores.

Muitas das críticas dirigem-se aos projetos pedagógicos dos cursos, aos programas das disciplinas e à atuação dos docentes. Por isso, coordenadores e professores têm buscado alguma forma de atualização, na tentativa de identificar o melhor caminho a seguir diante de difusas "exigências do mercado", procurando posicionar os cursos em conformidade com os quase sempre diáfanos "perfis de instituição", estabelecidos de forma esotérica, com grandiloqüentes declarações de visão, missão e objetivos. Em reação, os docentes envolvem-se com especificações de competências a serem desenvolvidas (incluindo sempre variado elenco de habilidades e atitudes), visando, em suas disciplinas, obter consonância com as demandas do "mercado globalizado" e do "posicionamento estratégico institucional". Documentos à parte, contudo, parece que, em termos de resultados, pouco tem mudado. Apesar da elevação da quantidade de quadros titulados, constata-se que não há correspondência entre o nível de titulação docente e o desempenho dos alunos dos cursos". Talvez, na ânsia de atender às "exigências do futuro", os Administradores estejam deixando de pensar em Educação.

$\mathrm{O}$ intuito deste texto é o de sistematizar e fundamentar reflexões sobre a formação de professores de Administração, independentemente do nível de titulação do docente, para que possa, quiçá, vir a contribuir à discussão geral em torno do tema. Considerando as características da área, a primeira parte do texto busca encontrar referenciais na interdisciplinaridade e na aprendizagem com pesquisa, por entendê-las como potencialmente contributivas, quer em si mesmas, quer ao ensino na Administração, para então, na segunda parte, apresentar proposições que retirem da primeira a base de fundamentação.

\section{INTERDISCIPLINARIDADE E APRENDIZAGEM COM PESQUISA}

A crescente constatação da natureza política do empreendimento educacional tem mobilizado todos os tipos e níveis de instituições e de grupos de interesse diretamente envolvidos com a Educação. O debate, porém, freqüentemente, mais tem feito aflorar disputas e sentimentos de insatisfação do que proporcionado desenlace efetivo, não obstante as múltiplas intervenções da autoridade pública no sistema. A 
diferença de visões leva à instalação de ambiente crítico em relação ao "modelo" educacional vigente, convergente em diagnóstico no que respeita à sua inadequação às necessidades do "mundo novo", mas não eficaz na formulação de propostas ou no encontro de soluções que possam ser aceitas de forma generalizada, apesar da interferência de organismos internacionais na área de Educação, como BIRD e FMI, mormente nos países periféricos, ditos emergentes ${ }^{2}$.

Se no âmbito externo, o das políticas públicas, o embate se instaura, na esfera acadêmica, o da produção de conhecimento, a polêmica se agrava pela existência de conflitos entre as várias áreas em que o conhecimento está dividido e, dentro delas, nos limites das disciplinas institucionalizadas, a aumentar a discórdia. Por isso, a produção acadêmica que se quer relevante, na Administração e nas demais áreas, está a perquirir abordagens cada vez mais abrangentes e complexas para ultrapassar os condicionamentos dos saberes disciplinares, entendidos como importantes, mas apercebidos em sua parcialidade. Ultrapassar a disciplinaridade é quase uma imposição de rigor, pois as disciplinas, imbuídas de seus pressupostos, métodos e jargões, constroem, constituem e instituem modos de ver o mundo que lhe são próprios. Como aponta Fourez (2000, p. 17), "as disciplinas científicas são modos historicamente organizados de produzir representações do mundo e colocá-los à prova".

Daí, também, a busca da construção de uma nova proposta metodológica para o ensino superior, que se caracterize por outro nível de integração dos saberes em diferentes e progressivos graus de complexidade. Se for possível aceitar que o primeiro estágio de complexidade corresponde àquele do saber das disciplinas, os demais graus poderiam suceder-se, em nível crescente: o segundo a equivaler à multidisciplinaridade, o terceiro à pluridisciplinaridade, o quarto à interdisciplinaridade, o quinto à transdisciplinaridade..., desde que houvesse consenso sobre seus significados e conteúdos.

Se entendermos, como Fourez (2000), que a multidisciplinaridade corresponde à "prática de reunir os resultados de diversas disciplinas científicas em torno de um tema comum, sem visar um projeto específico", enquanto a pluridisciplinaridade, ao se valer de contexto específico e de questões norteadoras, examina as perspectivas de diferentes disciplinas sobre uma problemática, "sem ter como objetivo a construção da representação de uma situação precisa", caracterizam-se na multidisciplinaridade e na pluridisciplinaridade dois níveis diferentes de complexidade. Contudo, como aponta Nicolescu, a pluridisciplinaridade "diz respeito ao estudo de um objeto de uma mesma e única disciplina por várias disciplinas ao mesmo tempo" e, apesar dessa fecundação ampliar e aprofundar o conhecimento do objeto em sua própria disciplina, faz com que a abordagem pluridisciplinar propicie ultrapassar as disciplinas, "mas sua finalidade continua inscrita na estrutura da pesquisa disciplinar" (NICOLESCU, 1999, p. 45). A mesma consideração aplica-se à multidisciplinaridade. 
É que Nicolescu, servindo-se de abordagem complexa e de fundamentação pouco ortodoxa, deposita sobre o conceito de transdisciplinaridade o mais alto grau de integração na busca do conhecimento. Nos seus termos, "a transdisciplinaridade, como o prefixo 'trans' indica, diz respeito àquilo que está ao mesmo tempo entre as disciplinas, através das diferentes disciplinas e além de qualquer disciplina. Seu objetivo é a compreensão do mundo presente, para o qual um dos imperativos é a unidade do conhecimento" (NICOLESCU, 1999, p. 46). A assunção fundamental do Autor, a embasar a busca dessa polêmica visão unificadora do conhecimento, é a da existência de vários níveis de Realidade, sempre negado pelo pensamento clássico. Como diz, "a transdisciplinaridade se interessa pela dinâmica gerada pela ação de vários níveis de Realidade ao mesmo tempo" (NICOLESCU, 2000, p. 16).

Assim, a interdisciplinaridade, por não aspirar "a unidade do conhecimento", mas tampouco se conformar ou ater-se ao inscrito "na estrutura da pesquisa disciplinar", pode emergir como alternativa à formulação de base metodológica para o ensino superior. Interdisciplinaridade, todavia, deve ser entendida sob duplo aspecto: arcabouço de conhecimentos e atitude diante do conhecimento. Se na acepção de arcabouço de conhecimentos aparece quase na condição de exigência natural a qualquer metodologia para o ensino superior que se almeje competente, é na acepção de atitude diante do conhecimento ${ }^{3}$ - de processo em que "é preciso olhar o fenômeno sob múltiplos enfoques, o que vai alterar a forma como habitualmente conceituamos", no dizer de Fazenda (2001, p. 15) -, que é possível imbuir-lhe a essência do fazer conseqüente.

Essa atitude primeira - a busca do fazer competente porque conseqüente -, é que, parafraseando Adorno, pode ajudar as pessoas a lidar com os conflitos objetivos que necessariamente se repetem em cada indivíduo, ao invés de serem ensinadas a esquecê-los. Entretanto, como destaca Cortella (2001, p. 115), "não há conhecimento que possa ser apreendido e recriado se não se mexer, inicialmente, nas preocupações que as pessoas detêm [...]" e as preocupações das pessoas, certamente, não se atêm ao âmbito do saber fragmentado das disciplinas, qualquer que seja a importância de cada uma delas, tomada isoladamente. A atitude diante do conhecimento influencia a própria produção do conhecimento e este, como diz o Autor, "é fruto da convenção, isto é, de acordos circunstanciais que não necessariamente representam a única possibilidade de interpretação da realidade" (CORTELLA, 2001, p. 104).

Numa base metodológica que aspire à qualificação de superior - não como mera referência à posição na estrutura do ensino, mas como condição de possibilidade à emancipação do estudante para que possa vir a aprender com autonomia, e qualificação do docente, para que, sempre estudante, possa manter sua maestria - há que se contemplar não apenas conteúdos teóricos e recursos didáticos facilitadores da aprendizagem, há de haver compromisso com os efeitos da prática sobre os agentes diretamente envolvidos. A abordagem interdisciplinar visa saber característico, além 
dos saberes disciplinares de que se vale: "procura construir sob medida uma perspectiva apropriada à singularidade da situação". Não obstante, em toda ação que necessita cooperação é preciso estabelecer uma representação que sirva de base, um espaço de racionalidade, que Fourez denomina de "ilha de racionalidade". Em seus termos:

\begin{abstract}
A pesquisa interdisciplinar - ou interdisciplinaridade stricto sensu - visa construir representações de situações precisas (ilhas de racionalidade) pela utilização das contribuições das disciplinas. Contrariamente à pesquisa disciplinar, que coloca os problemas em função das tradições das disciplinas, a pesquisa interdisciplinar retira seus critérios de pertinência do contexto de uma precisa situação considerada e nos projetos em vista dos quais se quer representada (FOUREZ, 2000, p. 7).
\end{abstract}

Além desse balizamento dos campos de estudo e de ação, Fazenda (1994) também caracteriza a atitude adequada ao pesquisador interdisciplinar, ao identificar aspectos sobressalentes às práticas pedagógicas bem sucedidas, entendido o sucesso como busca de construção de identidades pessoais e coletivas pela superação da dicotomia subjetividade-objetividade. A construção da identidade pessoal do professor é vista pela Autora como processo de gradativa tomada de consciência das próprias capacidades, das possibilidades oferecidas pelo ambiente e da probabilidade de executar trabalhos significativos, o que repercute na configuração de "projeto individual de trabalho e de vida", vinculado ao "projeto maior, o do grupo ao qual o indivíduo pertence". Esse vínculo só almeja o inquieto, o insatisfeito, "um sujeito portador de uma atitude comprometida em todas as suas afirmações e negações", que tem "o gosto por conhecer - por um conhecer em múltiplas e infinitas direções. É um ser que busca, que pesquisa" (FAZENDA, 1994, p. 48).

Essa mesma compreensão sobre o gosto de conhecer e da importância do papel emancipacionista da pesquisa na formação do sujeito, tanto do docente como do estudante, leva Lima a afirmar que "a construção do espaço escolar, no geral, e da sala de aula, em particular, precisa ser repensada e redesenhada sob outras bases, tendo em vista que os papéis tradicionais de professor e aluno, mestre e discípulo, provavelmente estarão mais próximos de uma relação construída entre pesquisador e orientador" (LIMA, 2000, p. 35).

Fazenda (1994) propõe, então, elenco de precisões para elaboração de projeto de capacitação à prática interdisciplinar da docência, que pode ir criando as condições para que sucessivas mudanças de estado - para outros de maior integração das identidades e saberes pessoais e coletivos -, possam levar ao estágio da interdisciplinaridade:

Um projeto de capacitação docente para a consecução de uma interdisciplinaridade no ensino precisa levar em conta: 
- como efetivar o processo de engajamento do educador num trabalho interdisciplinar, mesmo que sua formação tenha sido fragmentada;

- como favorecer condições para que o educador compreenda como ocorre a aprendizagem do aluno, mesmo que ele ainda não tenha tido tempo para observar como ocorre sua própria aprendizagem;

- como propiciar formas de instauração do diálogo, mesmo que o educador não tenha sido preparado para isso;

- como iniciar a busca de uma transformação social, mesmo que o educador apenas tenha iniciado seu processo de transformação pessoal;

- como propiciar condições para troca com outras disciplinas, mesmo que o educador ainda não tenha adquirido o domínio da sua (FAZENDA, 1994, p. 50).

No entender da Autora, a característica principal desse método - quer em decorrência do espaço fluído de delimitação do campo de estudo, quer pela crença de que a formação do pesquisador interdisciplinar se dará no decorrer dos processos interdisciplinares que sejam desencadeados e que o envolvam, mesmo que o pesquisador não tenha prontidão -, é ser fundamentado na ação, no "discurso interdisciplinar". Tomando-se por base o discurso, o método é dele decorrente. Tal método, em verdade, assenta-se sobre quatro aspectos principais: primeiro, o emprego da dinâmica maiêutica no processo de questionamento; segundo, a existência de liberdade e a ausência de direcionalidade das respostas; terceiro, o reconhecimento de que a construção depende do diálogo, da colaboração, da pesquisa e da consciência da "provisoriedade" das posições assumidas; quarto, o resgate da memória e das histórias de vida. Ou seja, para iniciar o percurso interdisciplinar e nele manter-se há que ousar ir sendo até ser: há que pôr nele o coração. E, como disse Pessoa (1999, p. 45), "o coração, se pudesse pensar, pararia".

Acresce que o emprego de tal método requer o envolvimento de todos os agentes com ele relacionados, numa ampla perspectiva. Subentende, como evidencia Sachot (2000), que a interdisciplinaridade não envolve a formação do docente apenas para o exercício de uma profissão. Não é apenas um método no qual, pelo qual e para o qual se deva preparar a formação do professor. Não repousa apenas na organização de saberes, em projetos pedagógicos ou em metodologias. Constitui o âmago da própria formação da pessoa humana. Professores e estudantes são compreendidos sob a mesma égide: pessoas humanas, capazes de formular juízos de valor e assumir responsabilidades, a orientar a formação dos professores àquela a ser proporcionada aos seus beneficiários, os estudantes. Diz Sachot:

A educação não é uma ciência e nem a aplicação de uma ciência ou de uma teoria savant! É um projeto político global que põe em congruência conjunto díspar de conhecimentos interdisciplinares que, felizmente, são mutáveis e estão constantemente em conflito (SACHOT, 2000, p. 12). 
Formidável desafio esse de interligar interdisciplinaridade, metodologia para o ensino superior e aprendizagem com pesquisa. Parece que se há de misturar um tanto de arte nesse fazer de ciência! Mas, como advertia Paulo Freire:

\begin{abstract}
A melhor maneira que a gente tem de fazer possível amanhã alguma coisa que não é possível de ser feita hoje, é fazer hoje aquilo que hoje pode ser feito. Mas se eu não fizer hoje o que hoje pode ser feito e tentar fazer hoje o que hoje não pode ser feito, dificilmente eu faço amanhã o que hoje também não pude fazer ${ }^{4}$.
\end{abstract}

Bronowski (1977) considera que um dos mais deletérios preconceitos de nosso tempo tem sido a comunidade científica considerar que a arte e a ciência são campos diferentes e incompatíveis. Possivelmente, por trás desse entendimento subjazem as crenças de que, primeiro, qualquer investigação que se queira merecedora de crédito dependa do rigor do método que a instrui, o que é difícil de negar, e, segundo, que para ser rigoroso e para ser científico o método deva revestir-se de tal austeridade, que há de ser vetusto, o que é difícil de aceitar.

Nas ciências humanas e sociais, em geral, e na Educação e na Administração, em particular, o estudante-pesquisador e o professor-pesquisador estão quase sempre diante de um quadro em que o emprego da racionalidade, em seu sentido mais estrito, é de alguma forma limitado. Isto por se verem obrigados a assumir hipóteses ou pressuposições sobre as características, condições e estados do ambiente ou do contexto e sobre as características, situações e estados do objeto - que se refletirão nas questões a serem convertidas em dúvida metódica, a justificar a pesquisa -, e, simultaneamente, por se verem premidos por essas mesmas condicionantes na seleção do específico método que antevejam como potencialmente mais adequados aos seus propósitos. Nessa delimitação da abordagem incluem-se, então, todo o referencial de aspirações e valores do pesquisador que é estudante ou professor, como conveniências metodológicas, malgrado o rigor empregado.

É que, em ciências humanas e sociais, a pergunta fundadora provém mais da sensibilidade para perceber, ex ante, o padrão ou o desvio que se embutem na realidade a ser explorada, ou nas categorias e atributos a serem analisados, do que do emprego de qualquer aparato de racionalidade. Por isso, a investigação que tende a ser mais contributiva é aquela engendrada por questionamento primordial arguto e sutil, que em seu próprio formular já faz antever a compreensão da complexidade dos fenômenos que busca ultrapassar: pura arte!

Pode parecer que, assim tratada e comparada às denominadas ciências duras, a aprendizagem pela pesquisa, em ciências humanas e sociais, tenda a certa acientificidade. Porém, por não ser de seu feitio a busca ou o encontro de relações de causa e efeito no sentido determinista, próprio das ciências exatas, exige elaboração 
teórico-prática complexa e sofisticada, para nela ancorar métodos e técnicas que possam ser considerados adequados e rigorosos. Apesar da rigorosidade, contudo, contrariamente ao que ocorre nas ciências duras, a teoria, nas ciências humanas e sociais, pode prestar-se à manipulação, de acordo com os interesses que em cada caso possam prevalecer. Popkewitz alerta que ela pode ser empregada para:

- fornecer base racional para mudar condições sociais e econômicas, fazendo essas mudanças parecerem razoáveis;

- fornecer mecanismo para legitimar interesses institucionais ou institucionalizados;

- orientar a preparação de planos sociais alternativos (POPKEWITZ, 1984, p. 12).

Daí advém a necessidade de compromisso e de responsabilidade, do estudante e do docente, pois em Educação e Administração os campos são propícios à manipulação e, por isso, patrocináveis e patrocinados. Entrementes, por requerer a presença desses atributos atitudinais, regidos pela moral e pela ética, é que uma base metodológica para o ensino superior calcada na interdisciplinaridade e na aprendizagem com pesquisa não pode ser nem estritamente racional, nem ingênua ou inconseqüente por "esquecer os conflitos objetivos". Flyvbjerg acentua que "a ciência social nunca foi e provavelmente nunca será apta a desenvolver o tipo de teoria explicativa e preditiva que é o ideal e a marca da ciência natural" (FLYVBJERG, 2001, p. 4). Mas, quanto a isso aspiram educadores e administradores... e seus patrocinadores!

Quando o estudante-professor-pesquisador almeja adotar atitude interdisciplinar diante da produção do conhecimento, por paradoxal que possa parecer, as dificuldades e as possibilidades aumentam.

Aumentam as dificuldades porque a atitude diante do conhecimento, influenciadora de sua própria construção, é a de buscar abordagens cada vez mais abrangentes e complexas para aqueles saberes que, durante toda a modernidade, se abrigaram no âmbito das disciplinas. Estas foram sendo criadas quase que por cissiparidade: à medida que os saberes acumulados em uma disciplina justificavam maior aprofundamento ou especialização, o que fora uma linha de pesquisa instituía-se em nova disciplina. É esse pretenso processo de racionalidade - que progressivamente afasta o conhecimento produzido de sua matriz geradora de referência, pela crescente introdução de pressupostos racionalizantes -, que permite a Nicolescu afirmar, em relação às ciências humanas, que "infelizmente, no mundo dos seres humanos, uma teoria sociológica, econômica ou política continua a existir apesar de múltiplos fatos que as contradizem" (NICOLESCU, 2000, p. 22). Na interdisciplinaridade o movimento é centrípeto, sem aspirar, porém, a unificação dos saberes, mas à sua integração: não por soma ou justaposição, mas por amálgama e multiplicação. 
Aumentam as possibilidades porque se ensejam condições à instauração de nova mentalidade, no sentido que propõe Japiassu (2001). Este Autor considera que é necessário valorizar um novo tipo de saber em que a noção de mentalidade aparece como sugestiva, pois "ao designar todo um conjunto de representações, atitudes, referências, comportamentos e motivações que se forjam e consolidam na prática, permite-nos compreender como é possível pensar de outro modo, segundo novas formas de "racionalidade"" (JAPIASSU, 2001, p. 73). Morin (2000) também entende que a busca do conhecimento objetivo envolve forçosamente a interação entre as estruturas mentais e a subjetividade do sujeito com o mundo exterior, sendo dele uma reconstrução, a implicar, portanto, numa ativa posição crítica, tanto em relação a si mesmo, quanto em relação ao mundo e ao próprio conhecimento.

Ora, se é possível pensar de outro modo, segundo novas formas de racionalidade e se a busca do conhecimento objetivo decorre da interação da subjetividade do sujeito com o mundo exterior, se é requerido ultrapassar a barreira dos saberes disciplinares, pela conjunção proporcionada por variados saberes dispostos de forma hologramática para ampliar a compreensão, mister se faz incorporar ao método toda a multiplicidade de recursos e procedimentos que, mantendo-lhe o rigor, incentivem a criatividade e a liberdade do estudante-docente-pesquisador. Só assim é possível proporcionar-lhe a construção de conhecimento que possa ir além do novo e encontrar o inusitado, para que, da perplexidade originada pelo estranhamento, surjam as fraturas que permitam a formação da nova mentalidade. Nada mais próximo da obra de arte! Como salienta Benjamin,

\footnotetext{
Sempre foi uma das tarefas essenciais da arte a de suscitar determinada indagação num tempo ainda não maduro para que se recebesse plena resposta. A história de cada forma de arte comporta épocas críticas, onde ela tende a produzir efeitos que só podem ser livremente obtidos em decorrência de modificação do nível técnico, quer dizer, mediante uma nova forma de arte. Daí porque as extravagâncias e exageros que manifestam nos períodos de suposta decadência nascem, na verdade, daquilo que constitui, no âmago da arte, o mais rico centro de forças (BENJAMIN, 1975, 29).
}

Assim deve o método ser entendido na interdisciplinaridade. Nela, liberdade e rigor não se opõem, como antagônicos. Liberdade é mesmo, em última instância, uma espécie de atributo do rigor, que dela precisa por querer-se livre, em sua rigorosidade, para não se tornar rígido, por não se querer rigorista a constranger a liberdade, para poder apreender o inaudito nas suas livres e plenas manifestações. Quer-se rigor no escrutínio do fenômeno, mas sabe ser o escrutínio posterior à sua emergência, compreende que é primeiro preciso captá-lo, por vezes em sua sutileza e fugacidade, já que depois haverá tempo e modo de interpretá-lo, não como elucubração ensimesmada do delírio, mas como alvo do cuidadoso percorrer do sentir e 
do pensar. Por sua vez, a liberdade, tem no rigor uma espécie de atributo, pois não se quer liberdosa, já que se entende conseqüente e compromissada. O rigor da liberdade é aquele do libertista e não do liberalão, pois se quer aberta ao novo e ao inusitado como possibilidade de encontro de alternativa naquilo que têm de novel, mas sem ser a novidadeira que a tudo acolhe sem reflexão. Quer-se liberdade na captação, na reflexão, na expressão, por isso rigorosa.

É este tipo de rigor que é requerido em Educação, em Administração e em educação na Administração. É este tipo de rigor que deve permear a metodologia de ensino que vise a formação do professor de Administração. Nele é possível pensar a formação do docente formador do administrador. No dizer de Quintás (s.d.), "viver criativamente caminha junto com pensar de forma rigorosa". É possível parafraseá-lo: pensar de forma rigorosa caminha junto com viver o método criativamente; nisso repousa a arte do docente pesquisador. Arte e estética são coisas bem diferentes, mas é da arte no engendramento do método que a pesquisa deriva sua estética. E é do saber fundamentado no método e compromissado com a prática que o docente deriva sua ética.

\section{FORMAÇÃO DO PROFESSOR DE ADMINISTRAÇÃO}

Se as considerações precedentes puderem ser levadas às suas conseqüências, é possível estabelecer delineamentos que permitam transpor as proposições gerais para o âmbito da formação do professor de Administração. Assim é que, parece, qualquer que seja o formato de programa que se almeje instituir, este tenderá a repousar sobre três pilares: formação do administrador, formação à docência, formação docente à Administração.

A formação do administrador parte da premissa que sua inserção no mundo do trabalho e da produção não pode ser encarada como a de uma ocupação ou profissão dentre outras, pelo potencial de influência da sua atuação sobre o derredor, tanto no cotidiano, como no longo prazo. Ocupação recente, decorrente da necessidade integradora de atividades crescentemente complexas, derivadas, primeiro, do industrialismo e, ultimamente, da internacionalização da produção e da globalização do mercado, tem-se empenhado tanto em criar corpo próprio de conhecimentos como recorrer à contribuição das mais variadas áreas, das de cunho técnico-científico às humanidades. De fato, não há como abordar a Administração como disciplina, mas sim como área de conhecimento, formada por teorias, métodos e técnicas, oriundos de diversas disciplinas e rearranjados para serem colocados à disposição do administrador, sempre às voltas com situações que demandam rearticulação do sabido, a incorporação de novos saberes e a confrontação com o inusitado.

Daí decorre que a formação do administrador requer visão abrangente - mas articulada, para ser estratégica - e qualificação diversificada - mas articulada, para 
saber trazer a estratégia à operação. A visão abrangente e integrada é requerida porque a internacionalização da produção e a globalização do mercado, ao ensejarem contínua divisão internacional do trabalho, ocasionam impactos sobre a capacidade competitiva das empresas, a exigir delas permanente esforço de análise, avaliação, formulação e reformulação estratégica. A qualificação diversificada se impõe porque a adoção de ações operacionais conseqüentes demanda: 1) conhecimentos específicos sobre as áreas funcionais críticas e os processos-chave dos negócios; 2) competência no trato de métodos, técnicas e tecnologias de apoio ao trabalho; 3 ) habilidade para relacionamento interpessoal profícuo; 4) atitudes que levem ao comprometimento com a sociedade e com a empresa e seus resultados; 5) a execução das tarefas e atividades de forma cooperativa e racional, em ambientes instáveis e competitivos, por mais contraditório que isso possa parecer.

A formação à docência - mais do que envolver métodos e práticas de ensino, articuladores de variadas dinâmicas instrucionais - requer a compreensão do papel da Escola e do Ensino, no geral, e do Ensino Superior, em especial, já que no ocidente e nos países ocidentalizados a Escola assumiu centralidade dentre as instituições sociais, ao passar a ser o lugar privilegiado em que se engendra boa parte da formação dos indivíduos. Seus conteúdos e valores, juntamente com aqueles oriundos das famílias, das religiões e das relações e modos de produção, quase sempre operando em mútuo reforço, mais do que constituintes são instituintes da mentalidade das pessoas, no sentido que lhe empresta Japiassu. No dizer de Silva, "as instituições educacionais processam conhecimento, mas também - e em conexão com esses conhecimentos - pessoas" (SILVA, 1995, p. 10), que compõem diferentes grupos sociais. Não há, pois, uma Educação e uma Escola, mas concepções de educação e de escola, a constituir sistema formado de processos educacionais que opera sob paradigma institucionalizado pelo Estado, o qual, por sua vez, é suscetível aos interesses dominantes: o denominado Estado Amplo, na significação que lhe atribui Bernardo (1998, p. 41) .

A Educação constitui apenas um dos pilares de sustentação da superestrutura ideológica, porém ela serve de suporte a três estruturas sociais fundamentais: a da cultura, a da organização social, a da distribuição do poder na sociedade, ou seja, carrega em seu bojo as mesmas contradições do processo de construção social, que não é internamente consistente e lógico. Mas, cultura não é repetição do passado, organização social não é determinismo, distribuição de poder não é imutável. O administrador, o administrador-docente e o docente-administrador têm muito a ver com isso, desde que se entendam, no exercício da profissão, como articuladores de esforços e recursos para suprir necessidades sociais e, no exercício da docência, como educadores.

A figura 1 procura ilustrar o contexto em que se dá a formação do administrador e da formação à docência, na Administração. 


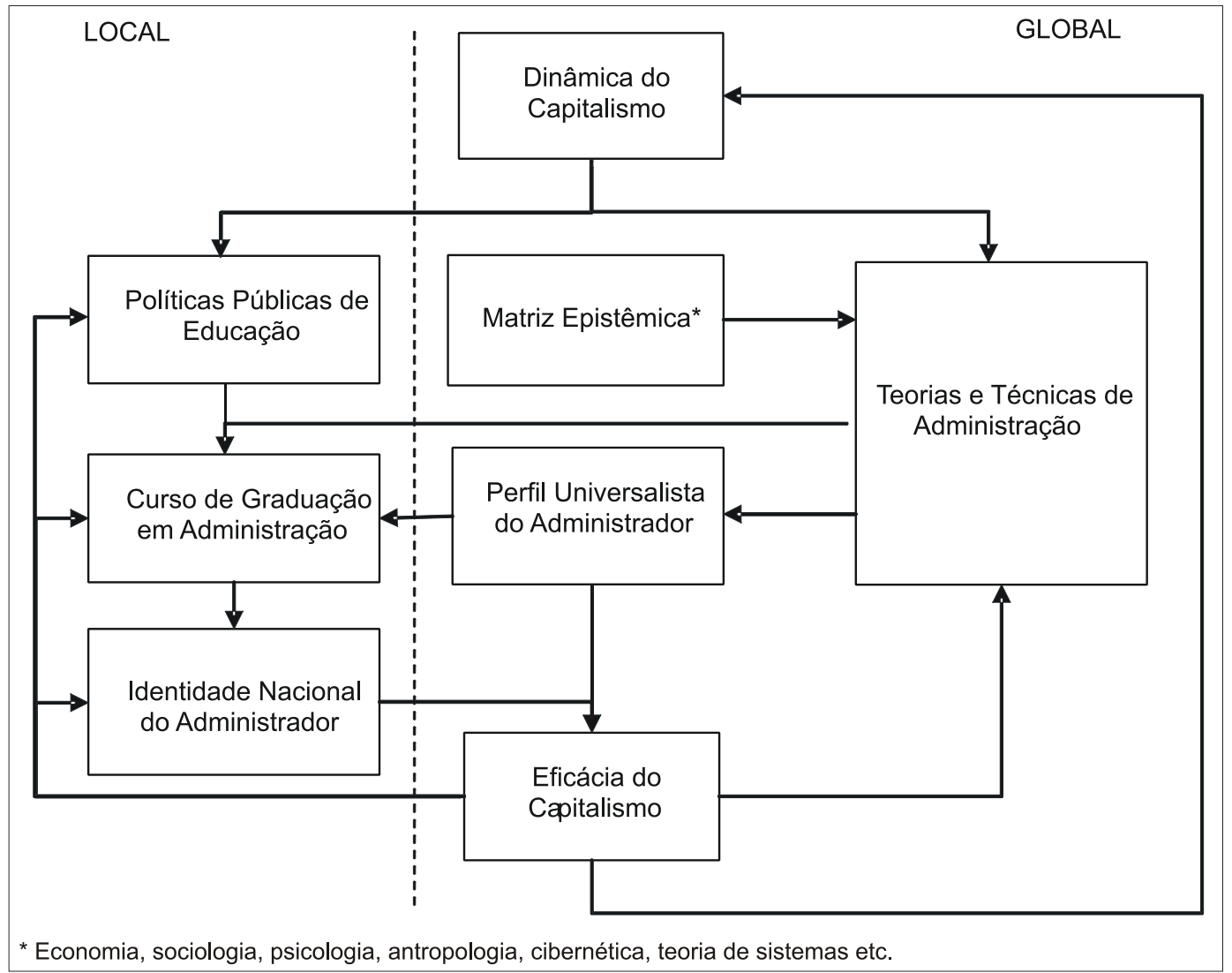

Figura 1 - Contexto do Curso de Administração

Fonte: elaborado pelo autor

O diagrama toma como ponto de referência a dinâmica do capitalismo, diretamente dependente de sua eficácia real. Esta, para que possa ser alcançada, repousa sobre ação intencional e contínua e, em sendo bem sucedida, sustenta àquela: como a constituir sistema auto-alimentado. O sistema, porém, além de auto-alimentado, quer-se auto-regulado e auto-regulante, pois, para manter a intencionalidade da ação na direção do proveito próprio, busca condicionar o ambiente de modo a favorecer-se. Ou seja, a eficácia do capitalismo é avaliada pela capacidade, velocidade e montante com que promove a acumulação de capital. Então, para ampliar a capacidade, incrementar a velocidade e aumentar o montante dos capitais, desencadeiam-se esforços no sentido de:

a) desenvolver conhecimentos voltados ao aprimoramento da gestão;

b) desenvolver gestores instruídos nesses conhecimentos e que possam ser instituídos como agentes aceitos e valorizados socialmente para aplicá-los; 
c) desenvolver instituições encarregadas tanto de promover a busca como a disseminação desses conhecimentos aplicáveis, que se alçam à condição de requisitos à obtenção de competências;

d) desenvolver atitudes, crenças e valores sociais consentâneos com o sistema e alimentadores do processo.

Ora, o modo de produção capitalista, ao se propagar até a sua absoluta prevalência, numa dinâmica evolutiva que Melucci (2001) denomina planetarização, passa a ser o indutor de modos e formas de organização, nos níveis global e local, os quais se imiscuem nas políticas públicas direcionando-as aos seus interesses, destacandose, entre elas, as voltadas à Educação, tomada e tornada, cada vez mais, Condição Geral de Produção, no sentido proposto por Bernardo:

\begin{abstract}
As Condições Gerais de Produção incluem todo o conjunto das infra-estruturas materiais, tecnológicas, sanitárias, sociais, culturais e repressivas indispensáveis à organização geral do capitalismo e ao seu progresso. [...] A concorrência na produção consiste, em última análise, na disputa entre os capitalistas para se ligarem da maneira mais favorável às Condições Gerais de Produção (BERNARDO, 1998, p. 31).
\end{abstract}

A capacitação docente à Administração e o docente em processo de capacitação têm que enfrentar desde logo seus duplos desafios: 1. entender se a formação do administrador deva concebê-lo como profissional potencialmente capaz de articular os saberes da área em nexo complexo, ou apenas como conhecedor de técnicas funcionais especializadas: mercadológicas, logísticas, financeiras...; 2. entender se a formação do docente deva concebê-lo como educador, ou apenas como instrutor técnico na sua área de saber específico, dotado de didática. A perspectiva de se empregar a interdisciplinaridade e a aprendizagem com pesquisa repousa sobre as mais elevadas dessas compreensões. Por isso, a elaboração de construto que as encampem deve, primeiro, calcar-se na compreensão do contexto, com as implicações dele decorrentes e, segundo, promover articulações de conceitos e conteúdos que as respeitem, articulem e ensejem.

A figura 2, a seguir, busca evidenciar como essas relações podem ser estabelecidas. Apresenta, no topo, envolto em retângulo pontilhado, o esforço para formação do professor de Administração como assentado sobre pano de fundo em que, por um lado, insere o Ensino Superior na estrutura de ensino vigente e, por outro lado, articula a área de Administração no âmbito do Ensino Superior. É dentro desse complexo ambiente - em que se justapõem e por vezes se sobrepõem os órgãos reguladores, gestores e fiscalizadores das políticas públicas da Educação, a originar em sua azáfama numerosos regulamentos e procedimentos - que se delineia o espaço das possibilidades dos fazeres educativos gerais e específico. 


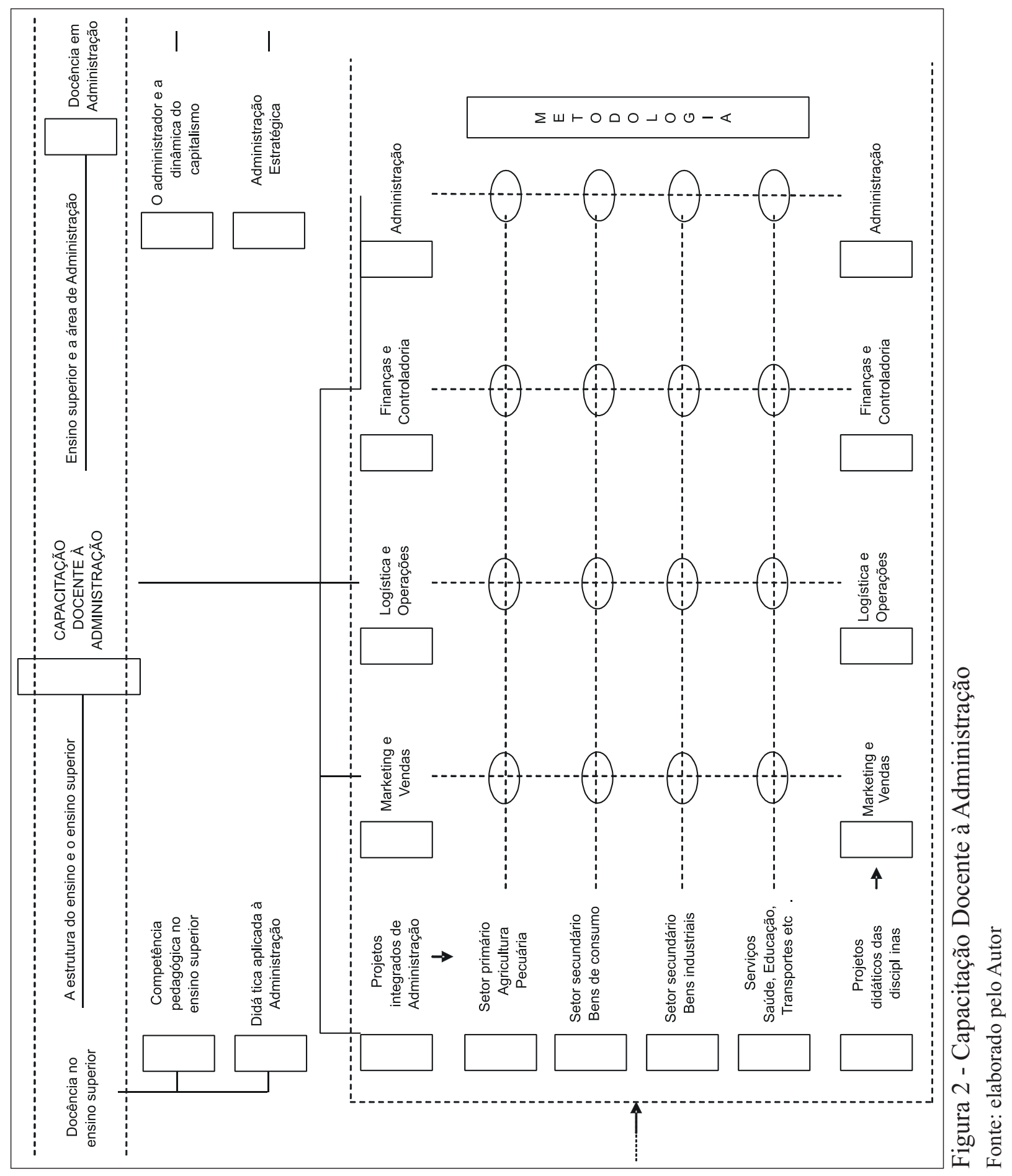


Abrem-se, então, duas importantes vertentes ao mesmo tempo reflexivas e orientadas à ação, envolvendo a docência em Administração e a docência no Ensino Superior. Essa ordem, que pode parecer invertida à primeira vista, é especialmente relevante desde que se aceite, como indicado na Figura 1, a sobrevalência, no capitalismo, das exigências advindas da busca da eficácia, genitora de sua dinâmica, em relação à formulação das políticas públicas nacionais, condicionando-as. Dentro dessa dinâmica é que o administrador encontra seu lócus, por isso mister entendê-la. Mas, além da compreensão da mecânica que lhe subjaz, é requerido apreender-lhe em suas exigências, constrangimentos e perspectivas, isto é, tomar consciência de suas implicações no condicionamento do modus vivendi de ontem e de hoje e das perspectivas futuras, pois, certamente, a evolução não é linear.

A demanda que esse exercício impõe e os raciocínios que permite engenhar são característicos do pensamento estratégico, único capaz de instruir uma administração estratégica. Esta, mais do que nunca é requerida, independentemente de aquele que administra ser oriundo de curso de Administração. O pensar estrategicamente é essencial à prática da interdisciplinaridade, de tal forma que, aquele que o exercita passa, repetindo Fazenda (1994), "a olhar o fenômeno sob múltiplos enfoques, o que vai alterar a forma como habitualmente conceitua". Este olhar não ingênuo é essencial à aquisição de competências pedagógicas relevantes - no âmbito da elaboração de projetos pedagógicos, de currículos, do planejamento didático, da relação professor-aluno, enfim, do fazer educativo -, pois primeiro educa o educador e, em assim fazendo, condiciona todo o processo subseqüente, que disso se vale para o fazer conseqüente.

O fazer competente, porém, requer configuração em que se possam mesclar as teorias e técnicas de Administração com a possibilidade de sua aplicação prática fundamentada, isto é, valer-se da pesquisa e do método científico para construir saberes significativos à área, ao profissional e à docência. Para tal, como propõe Fourez, é preciso estabelecer alguma "ilha de racionalidade", que possibilite o exercício da interdisciplinaridade. Ilhas de racionalidade podem apresentar-se sob a forma de projetos de pesquisa, que demandem, simultaneamente, aporte teórico e aplicação prática, a exigir que, em cada projeto, se faça presente ampla gama de conhecimentos para poder levá-lo a bom termo, a possibilizar aos participantes a compreensão abrangente e integrada do objeto de estudo. Ora, para administradores, parece, o melhor enfoque para referir a teoria à prática e o empírico à formulação teórica talvez corresponda àquele em que a ilha de racionalidade seja a empresa, tida como objeto de estudo. Mas, que tipo de empresa? De que porte? De que setor?

O administrador, se a Administração e o administrador tiverem caráter internacionalista, tem que estar apto a envolver-se, no que respeita às organizações, com as de diversas naturezas e finalidades; no que tange especificamente às empresas, com 
as dos setores primário, secundário e terciário da economia. $\mathrm{O}$ objeto de estudo e de pesquisa, porém, enquanto trabalho acadêmico voltado à aprendizagem, não requer o contato efetivo com empresas, mas à configuração daquela que pode ser considerada como típica, no sentido que lhe propõe Weber (1991) $)^{6}$, em cada um dos departamentos da economia - agrícola, extrativo, criatório, no departamento I; indústrias de bens de consumo e de bens industriais, no departamento II; serviços, em suas variadas naturezas, no departamento III -, na específica região de atuação ou de influência do curso ministrado. Ou seja, tomando-se as efetivas vocações econômicas regionais, é possível configurar uma empresa típica para cada um dos departamentos da economia e, com base nela, que é fictícia, mas inserida em ambiente amplo, que é real e precisa ser pesquisado, discutir e formular projeto integrado de administração para seu posicionamento estratégico, visando a auto-sustentação, como se efetivamente fosse ser implantada. Para tal, ao projeto devem confluir conhecimentos, tanto do contexto econômico preciso em que se situa a empresa-tipo, como das áreas-chave em que se pode, genericamente, subdividir qualquer empresa-tipo: Marketing-Vendas, LogísticaOperações, Finanças-Controladoria. A área de Administração pode envolver-se com o aporte de dois conjuntos de contribuições, no setor sob estudo: 1. situação de oferta e demanda de trabalho, condições de trabalho e de emprego, formas e tipos de contratação e remuneração; 2. recursos de tecnologia de informação aplicáveis às específicas condições da empresa-tipo e do posicionamento estratégico para ela pretendido.

Desse modo, pela aplicação dos conhecimentos de cada área-chave e das áreas de apoio aos contextos de quatro diferentes projetos, que abarcam os departamentos da economia, é possível ultrapassar as generalizações propostas em cada uma delas para apreendê-las em sua multiplicidade aplicativa, salientando os conceitos centrais efetivamente relevantes. Como conseqüência, propicia-se embasamento, em cada área chave, para a elaboração de projetos didáticos das disciplinas, pois, ao ter exposto o docente à compreensão dos aspectos dos contextos sócio-econômico-político-educativos que envolvem o ensino superior na área de Administração, bem como dos contextos sócio-políticoeconômicos a que se referiram os projetos, possibilitam articulações bem fundamentadas, já que não é possível, como salienta Mattos, ir muito além do senso comum:

Historicamente, a ciência ocidental sempre procurou distinguir-se dele, e não seria difícil para a academia sustentar que a teoria administrativa corrente no mercado não vai muito além do senso comum bem informado e com boa retórica (MATTOS, 2003).

\section{CONSIDERAÇÕES FINAIS}

A formação do professor de Administração está a merecer a atenção da comunidade envolvida com essa área de conhecimento e o investimento de mante- 
nedores de instituições privadas e públicas, como constatam Souza-Silva e Davel (2005) ao indicarem a carência de políticas de formação de professores no ensino de Administração. É preciso criar o espaço-tempo que enseje o estudo dos assuntos tidos como de interesse direto dos docentes da área: Administração, Educação, docência, docência em Administração.

Entende-se, porém, que os esforços precisam ultrapassar aqueles da tradicional transmissão de conteúdos, típicas do processo de escolarização, para avançar em direção às pesquisas: não apenas as solitárias, das dissertações e teses, próprias da pós-graduação stricto sensu, mas as solidárias, que envolvem grupos de estudo em interação. Caso contrário instaura-se o que Festinalli (2005) aponta como uma visão de ensino separado da pesquisa, a alimentar o distanciamento entre pesquisadores e profissionais que exercem a docência: aqueles carentes de experiências, estes excessivamente nelas calcados, a desenvolver ações "que não são descritas com precisão, mas evidenciam a existência de um saber que se constrói no fazer" (FESTINALLI, 2005, p. 137). A preocupação central, então, há de repousar sobre uma relação teoriaprática referida ou inserida nas condições do ambiente e das características das regiões de atuação dos envolvidos, a instruir processo interdisciplinar e socialmente conseqüente de apropriação de conhecimento, na medida em que é a atuação em contexto específico que faz aflorar as exigências e os constrangimentos que irão confrontar o que é tido como sabido. É a isso que se refere Fazenda (1994) ao caracterizar as práticas interdisciplinares bem sucedidas: a construção de identidades pessoais e coletivas possibilitadas pela execução de trabalhos significativos, que vinculam o trabalho individual ao projeto do grupo ao qual o docente pertence.

De fato, o esforço de capacitação docente subsume autoqualificação e autoformação: professores buscam gerar processos e produtos que possam propiciar a reflexão sobre seus misteres. Processos e produtos que embasem a competência, ou seja, alimentem-nos de recursos cognitivos, metódicos e racionais, a par de condições emocionais, comportamentais e atitudinais, para que sejam mobilizados no momento da ação. Isto é competência: capacidade de escolher e adotar ações ajustadas às exigências das contingências vividas, à medida que elas se apresentem. Como enfatiza Lima (2005), reportando-se às conseqüências do processo para professores e estudantes:

\footnotetext{
Em oposição aos manuais de didática que ambicionam propor soluções gerais para problemas locais, o trabalho realizado pelos professores participantes dos grupos de aprendizagem reflexiva além de promover a consciência dos problemas enfrentados pelo exercício do diagnóstico, desencadeia a aprendizagem coletiva capaz de fortalecer a elaboração de alternativas de intervenção [...]. Esta aprendizagem vivenciada gera a consciência de que não há fórmulas milagrosas para problemas humanos, conseqüentemente, o trabalho realizado pelos grupos de formação reflexiva é processual (LIMA, 2005, p. 46).
} 
A escolha de projetos integrados de administração para empresas-tipo como instrumento de formação interdisciplinar do professor de Administração, possibilita aprendizagem ampla e integrada: domínio de processos, geração de produtos, além de combinar a proposta própria da abordagem PBL - Problem-based Learning, com o conceito de competências-chave (Key Competencies): vale-se de problemas reais como ponto de partida, desenvolve atributos cognitivos, relacionais e comportamentais, em ambiente adulto, profissional e instruído (Learning in adulthood), que operam em mútuo reforço, como salientam Tien, Ven e Chou (2003)7. Para além dos recursos de que se vale, contudo, deve-se mirar, prospectivamente, a efetiva contribuição que possa prestar ao desenvolvimento da área, da profissão e delas no desenvolvimento da condição de vida das gentes. Afinal, o mais importante talvez seja refletir Aktouf, quando diz:

\begin{abstract}
Para mim, o futuro do professor de administração deve ter: a) uma sensibilidade humana e desviar da norma do ensino tradicional de administração; b) uma grande cultura geral; e c) uma experiência de campo. Essas qualidades estão no extremo oposto da mercantilização do saber e do professor (AKTOUF, 2005, p. 158).
\end{abstract}

\title{
TEACHER'S INTERDISCIPLINARY EDUCATION IN ADMINISTRATION
}

\begin{abstract}
The boundary expansion of the Administration area has taken it to constitute specialized sub-divisions to the detriment of holistic point of view, more and more necessary. This fragmenta-tion process forces the inclusion of new subjects in the curriculum of the undergraduate cour-ses, in order to keep them up-to-date. It seems, however, that this diversity of subjects has caused, to teachers and students, more bewilderment than the expected comprehension. This paper discusses the idea that the success of graduation course in Administration may depend on a wide and integrated education of its teachers. The alternative proposed is the adoption of an education program of teachers, based on an interdisciplinary approach and learning with research orientation, in order to allow them get a comprehensive vision of the Administration areas, apart the subjects they may teach, and find paths to a firm and coherent praxis that may take the students to their autonomy.
\end{abstract}

Keywords: Education of Administration Teachers. Administration Education. Administration Learning. Interdisciplinarity in Administration. Education with Research in Administration. 


\section{NOTAS EXPLICATIVAS}

1 O assunto é abordado em ANDRADE, R. O. B.; LIMA, M. C. e TORDINO, C. A.. O que podemos aprender com os cursos 5A? São Paulo: Makron Books, 2001, p. 92.

2 Entre outros, os textos de Marília FONSECA, O Banco Mundial e a Gestão da Educação Brasileira e de Dalila Andrade OLIVEIRA, Educação e Planejamento: A Escola como Núcleo da Gestão, inseridos na coletânea Gestão Democrática da Educação (1997), organizada por esta última autora, indicam a importância desses organismos na formulação de políticas públicas na área da Educação.

3 "Pour être capable de faire du travail interdisciplinaire, iffaut avoir appris une competence qu'on pourrait appeler 'le bon usage des spécialises et des savoirs spécialisés"' (FOUREZ, 2000).

4 Citado por: Cortella, Mário Sérgio. Paulo Freire: Utopia e Esperança. Conferência proferida no V Colóquio Internacional Paulo Freire - Recife, 19 a 22 de setembro de 2005. Disponível em www. paulofreire.org.br/Textos/ Conferência\%20de\%20Cortella.pdf.

5 "Por oposição ao Estado Restrito, que inclui apenas o aparelho político reconhecido juridicamente, e tal como é definido pelas Constituições dos diversos países, ou seja, o governo, parlamento e tribunais, o Estado Amplo inclui todas as formas organizadas do poder das classes dominantes" (BERNARDO, 1998, p. 41).

6 "Obtém-se um tipo ideal mediante a acentuação unilateral de um ou vários pontos de vista, e mediante o encadeamento de grande quantidade de fenômenos isoladamente dados, difusos e discretos, que se podem dar em maior ou menor número ou mesmo faltar por completo, e que se ordenam segundo os pontos de vista unilateralmente acentuados, a fim de se formar um quadro homogêneo de pensamento. Torna-se impossível encontrar empiricamente na realidade esse quadro, na sua pureza conceitual, pois trata-se de uma utopia. A atividade historiográfica defronta-se com a tarefa de determinar, em cada caso particular, a proximidade ou afastamento entre a realidade e o quadro ideal [...]" (WEBER, 1991, p. 106).

7 "Key competencies, the foundations of professional learning, continuing learning and lifelong learning, have been emphasized by many advanced countries and integrated into the course content and teaching process. The PBL, driven learning with problems related to real life situations, is emphasizing independent learning and small group cooperative learning, provides environments and opportunities to improve the key competencies" (TIEN et al, 2003, p. 459).

\section{REFERÊNCIAS}

AKTOUF, Omar. Ensino de Administração: por uma pedagogia para a mudança. Organizações e Sociedade, v. 12, n. 35, p. 151-159, out./dez. 2005.

BENJAMIN, Walter. A obra de arte na época de suas técnicas de reprodução. São Paulo: Abril Cultural, Os Pensadores, vol. XLVIII, 1975.

BERNARDO, João. Estado: a silenciosa multiplicação do poder. São Paulo: Escrituras Editora, 1998.

BRONOWSKI, Jacob. O senso comum da ciência. São Paulo: Editora da Universidade de São Paulo, 1977. 
CORTELLA, Mário Sérgio. A escola e o conhecimento: fundamentos epistemológicos e políticos. 4. ed. São Paulo: Cortez: Instituto Paulo Freire, 2001.

FAZENDA, Ivani Catarina Arantes. Interdisciplinaridade: história, teoria e pesquisa. Campinas: Papirus, 1994.

FAZENDA, Ivani Catarina Arantes (Org.). Interdisciplinaridade: dicionário em construção. São Paulo: Cortez, 2001.

FESTINALLI, Rosane Calgaro. A formação de mestres em administração: por onde cami-nhamos? Organizações e Sociedade, v. 12, n. 35, p. 135-150, out./dez. 2005.

FLYVBJERG, Bent. Making social science matter: why social inquiry fails and how it can succeed. Cambrigde (UK): Cambridge University Press, 2001.

FOUREZ, Gérard. Fondements épistemologiques pour l'interdisciplinarité. In: CONGRESSO INTERNACIONAL DA ASSOCIAÇÃO MUNDIAL DAS CIÊNCIAS DA EDUCAÇÃO. 13, 2000, Canadá. Texto provisório: Universidade de Sherbrooke, Québec, Canadá, 2000.

JAPIASSU, Hilton. Desistir de pensar? nem pensar. São Paulo: Letras \& Letras, 2001.

LIMA, Manolita Correia. Ensino com pesquisa: uma revolução silenciosa. São Paulo: M.C.Lima, 2000.

LIMA, Manolita Correia. Ensino, Pesquisa, Capacitação e Titulação Docente no Ensino de Graduação em Administração. In: ENCONTRO NACIONAL DOS CURSOS DE GRADUAÇÃO EM ADMINISTRAÇÃO - ENANGRAD. 16, 2005. Disponível em: <www.angrad.org.br/xvienangrad>. Acesso em 10 set.2006.

MATTOS, Pedro Lincoln C. L. O que diria Popper à literatura administrativa de mercado? Revista de Administração de Empresas, v. 43, n. 1, p. 60-69.jan/fev/ mar, 2003.

MELUCCI, Alberto. Vivencia y convivencia. Teoria social para una era de la información. Madrid: Editorial Trotta, 2001.

MORIN, Edgar. Saberes globais e saberes locais: o olhar transdisciplinar. Rio de Janeiro: Garamond, 2000. 
Formação interdisciplinar de professores de Administração

NICOLESCU, Bassarab. O manifesto da transdisciplinaridade. São Paulo: TRIOM, 1999.

NICOLESCU, Bassarab. Um novo tipo de conhecimento - transdisciplinaridade. In: NICO-LESCU, Bassarab et al. Educação e Transdisciplinaridade. Brasília: UNESCO, 2000.

PESSOA, Fernando. Livro do desassossego: composto por Bernardo Soares, ajudante de guarda-livros na cidade de Lisboa. São Paulo: Companhia das Letras, 1999.

POPKEWITZ, Thomas S. Paradigm and ideology in educational research. Philadelphia, PA: The Falmer Press, 1984.

QUINTÁS, Alfonso López. El secreto de uma enseñanza eficaz. Madri: Universidad Complutense, mimeo, sd.

SACHOT, Maurice. L'interdisciplinarité de la formation du professeur dans son rapport à celle de l'élève. CONGRESSO INTERNACIONAL DA ASSOCIAÇÃO MUNDIAL DAS CIÊNCIAS DA EDUCAÇÃO. 13, 2000, Canadá. Texto provisório: Universidade de Sherbrooke, Québec, Canadá, mimeo, 2000 .

SILVA, Tomaz Tadeu da. Apresentação. In: GOODSON, Ivor F. Currículo: teoria e história. Petrópolis, RJ:Vozes, 1995.

SOUZA-SILVA, Jader C. de; DAVEL, Eduardo. Concepções, Práticas e Desafios na Formação do Professor: Examinando o Caso do Ensino Superior de Administração no Brasil. Organizações e Sociedade, v. 12, n. 35, p. 113-134, out./dez.2005.

TIEN, Chen-Jung; VEN, Jui-Hung; CHOU, Shoh-Liang. Using the Problem-based Learning to Enhance Student's Key Competencies. The Journal of American Academy of Business, Cambridge, p. 454-459, Mar, 2003.

WEBER, Max. A 'objetividade' do conhecimento nas ciências sociais. In: COHN, Gabriel (Org.). Weber. São Paulo: Ática, 1991. 